\title{
Signos, marcas e iconos de la modernidad en la poesía rebelde e irónica de Luis Bagué
}

\author{
Francisco Javier DíEz DE REvENGA \\ Universidad de Murcia
}

\begin{abstract}
Desde los comienzos de su aventura poética en 2002, Luis Bagué muestra en su poesía una visión de la modernidad que refleja un mundo de asombros, para pasar posteriormente a realizar una reflexión sobre el tiempo y el trascurrir de la existencia, poblada por muy diversos afanes. Un consciente y severo proceso de autoanálisis, de introspección, define la realidad descubierta a través de diversos signos e iconos, aunque universalice sentimientos a la luz de una visión irónica de la vida contemporánea entrevista con un defensivo sentido del humor.

Keywords: Luis Bagué, poesía, modernidad, iconos, signos
\end{abstract}

Con Telón de sombras ${ }^{1}$ inicia Luis Bagué Quílez (Palafrugell, Gerona, I978) su personal aventura poética en 2002 . La poesía en este libro contenida ya anuncia la solidez de un mundo poético que el autor va trazando sobre la base de tres series de estampas o retratos de seres extraídos de la realidad y recreados con un lenguaje que bordea la irracionalidad para expresar no solo la contemplación de mundos concretos sino la superación de esa misma realidad para alcanzar una compresión de seres reales e imaginarios como participantes de un mundo de asombros. En principio podría parecer, sobre todo en la primera serie de estos poemas, que el autor, a la manera de una poesía de base tradicional, se recrea en la contemplación de unos determinados oficios que podrían sugerirnos tonos costumbristas, como luego hará en las otras dos series con parecida intención descriptiva.

Pero nada más alejado de la verdad poética de estas configuraciones presididas por un título sugerente que envuelve, en efecto, una realidad que se sublima en el consiguiente análisis estructural. Podríamos decir que el poeta lo que hace es enfrentarse a mundos ajenos sugeridos por un oficio, por una realidad histórica o por una configuración mítica y, ante los elementos que le ha legado una cultura de observador de la realidad, emprende su propia independencia analítica para expresar una configuración de su mundo poético como aventura personal.

Sin duda estamos frente a una poesía de iniciación y asombros ante mundos cotidianos que se transforman por virtud de una palabra poética, en ocasiones agresiva, que trata de superar esa cotidianidad para sublimarla en representaciones personales y en concepciones críticas ante mundos

I Luis Bagué, Telón de sombras, Madrid, Hiperión, 2002. 
complejos. Solo una palabra poética vibrante, de gran cohesión formal y argumental, puede llegar a crear un mundo que en el fondo se entrevé tras ese telón de sombras que aparece en el título del libro. Visión, por tanto, muy personal de figuras y espacios que surgen de la propia realidad diaria y de la tradición intelectual asumida para alcanzar una reflexión que va mucho más allá de lo cotidiano con el fin de internarse en una reflexión metafísica sobre la existencia, las creencias, en definitiva, el mundo intelectual adquirido en la adolescencia y primera juventud, que ahora se somete a una severa revisión personal en busca de respuestas a mundos que están en la propia existencia del poeta.

Mientras que en la primera parte del libro la reflexión sobre el mundo se centra en personajes vinculados a un oficio o a una actividad (El jardinero, El pintor, El profesor, El pescador, El tatuador, El mendigo, El asesino...), que representan una visión del mundo a través de colectivos humanos y desarrolla reflexiones sobre la existencia, en la segunda comparecen una serie de sugerencias que van mucho más allá (Los muertos, Los bañistas, Las novias, Los abuelos, Los amantes, Los borrachos, Los amigos...) y que tiene como trasfondo temas eternos como la muerte, la edad y el tiempo, las relaciones familiares, el amor y la pasión, hasta configurar una visión global de un mundo que transcurre implacablemente. Por eso la tercera parte contrasta con las anteriores al internarse en los terrenos de lo mítico y lo legendario (Los dioses, Los centauros, La tejedora, Las sirenas, Los ángeles, Las estatuas...), y descubrir en el mundo de la imaginación y de la tradición culta nuevos elementos que responden al análisis global de la existencia que ofrece este Telón de sombras, en su conjunto y a través de sus tres partes o secciones. Indudablemente es la solidez de todo el libro y la cohesión de sus distintas secciones las que dotan a este poemario de un poder de convicción incuestionable al que contribuye también la complicidad de unas estructuras formales y una belleza expresiva establecida con un verso elegante y efectivo.

Tras el libro Babilonia, mon amour ${ }^{2}$, escrito en colaboración con Joaquín Juan Penalva, publica Bagué en 2006 El rencor de la luz 3 . Y llama la atención en este libro la recurrencia, por parte de Bagué, a frases hechas de la vida cotidiana para titular los poemas de las tres primeras secciones que lo integran. Así, en la primera, con su único poema, «Los pasos perdidos»; en la segunda, con "Canciones dedicadas», «Piezas de museo» "Ciudades de paso», «Después de la batalla» 0 «[Ciudad] tras los visillos». «Camafeos», que cierra la sección segunda, ya anticipa las denominaciones de los poemas de la tercera, alusivos a géneros y títulos pictóricos, como «A la ventana», «Pai-

2 Luis Bagué-Joaquín Juan Penalva, Babilonia, mon amour, Murcia, Universidad de Murcia, 2005.

3 Luis Bagué, El rencor de la luz, Talavera de la Reina, Colección «Melibea», 2006. 
saje con luna», «Paseo a orillas del mar», «Bodegón», «Acuarela», «Las hilanderas», lo que pone de relieve una tendencia que se convertirá en signo distintivo de la poesía última de Luis Bagué: la recurrencia a signos, marcas o iconos del imaginario colectivo asumidos habitualmente por la civilización coetánea. El gato de porcelana que engaña la vista parece aludir a la frase «ves menos que un gato de porcelana» y las «vísperas de fiestas de guardar» anuncian tendencias a paladear frases hechas que se desarrollarán en los libros siguientes...

Sin apartarnos nada de este campo de la tendencia tituladora del poeta, no podemos dejar de aludir a la singularidad de los títulos de la cuarta sección de este poemario, referida a lugares del trazado urbano de la ciudad de Alicante, ya sea a través de sus calles o de algunos entornos singulares. Así, «Calle del Mercado», «Castillo de Santa Bárbara», «Minicines Astoria's», «Calle del Teatro», «Avenida Alfonso 'El Sabio'», «Playa del Postiguet», «Muelle de Poniente, «Calle Los Olmos»...

En su conjunto, evidentemente El rencor de la luz es un libro de nostalgias que anuncia una reflexión sobre el tiempo y el trascurrir de la existencia, poblada por muy diversos afanes que detienen al poeta en consideraciones de importancia vital. Si en el poema inicial, en forma de prólogo programático, se evidencia el trascurrir de la vida a través de unos pasos perdidos, esos pasos tratan de superar la inconsistencia de su levedad y quedan fijados en las imágenes y sugerencias que se van a suceder en las diferentes secciones de este libro poético, que deja sentir la tensión del tiempo en cada una de sus estancias, como se advierte en aquellos objetos abandonados en el desván «donde se niega el tiempo», con afirmación más que inquietante. Todos y cada uno de los poemas de esta sección envolverán girones de existencia que se confirmará en la tercera del libro, la dedicada a una serie de pinturas (Murillo, Sorolla, Velázquez y otros cuadros anónimos), en cuya contemplación se esfuerza el poeta por mantener la tensión del tiempo en aquellos cuadros intuida... Y, del mismo modo, la vivencia de los espacios urbanos familiares de la última sección reiterará nostalgias que enriquecen la memoria y que pugnan por superar el olvido a que están destinadas aquellas vivencias que enriquecieron otros tiempos y otros aconteceres. Tales devenires no merecen ser sepultados por la ausencia de una memoria que la palabra poética se encarga de fecundar, aunque el poeta, con un cierto punto de decepción sobre su traba como escritor, avise que «de nada sirve aventurar metáforas / conjeturar imágenes fugaces» ${ }^{4}$.

En 2007, en su libro Un jardín olvidado ${ }^{5}$, con planteamientos de gran originalidad, el poeta traza a través de las composiciones de este libro un mundo

4 Luis Bagué, El rencor de la luz, op. cit., p. Io.

5 Luis Bagué, Un jardín olvidado, Madrid, Hiperión, 2007. 
poético de extracción muy personal, en el que su propia existencia, sus recuerdos, sus planteamientos vitales, mucho tienen que ver con su manera de enfocar el mundo contemporáneo, con sus olvidos y desmemorias. Al poeta le interesa convencer a su lector de que sus planteamientos le pueden comprometer y compartir con él sus reflexiones sobre el mundo y sobre la vida.

Y es que la colección ofrece una serie de representaciones a través de las cuales el poeta va descubriendo a su lector un mundo de memoria que pugna, una vez más, como en los libros anteriores, contra un irremediable olvido. El jardín representa, renovando un viejo tema poético, al paraíso perdido, el paraíso de los años que han trascurrido no hace mucho, los años de la adolescencia y primera juventud, junto a los más candorosos de la infancia, recuperada también en su inocente recuerdo. Pero está también el momento actual, con su intensa vivencia amorosa y prendido al anhelo, si no es posible recuperar el jardín olvidado, de buscar al menos los espacios en los que gozar de la dicha del presente.

Articula Bagué su libro en cinco secciones que acogen desigual número de poemas, pero que reúnen cada una de ellas homogéneas representaciones poéticas. Tras un preámbulo, «Este lado del paraíso», en el que el poeta, programáticamente, nos advierte en qué lugar nos encontramos, y exactamente en qué momento el poeta muestra su vivencia amorosa, se suceden luego secciones diferentes. Una «cartografía» donde la memoria se vincula a lugares concretos de una geografía sentimental en la que rincones, paisajes, esquinas urbanas, combinan la intensidad de lo real con la fuerza de lo soñado, para recrear mundos ya transcurridos, pero que permanecen indelebles en la memoria.

Sin duda, la zona más expresiva de todo el volumen la constituye la parte tercera, central en el poemario, que acoge el título del libro como denominación propia, «Un jardín olvidado», y a la que se incorporan poemas en los que la superación de la realidad se consigue con un lenguaje diferente, más exigente, impresionista y de un alto y logrado simbolismo, como se expresa en el poema inicial, titulado justamente «Símbolos», conjunto metapoético que adquiere un sesgo programático. Y así lo advertimos, desde luego, en los poemas subsiguientes, en los que volvemos a descubrir el anhelo del jardín perdido junto a la presencia de los enemigos de siempre, como manzanas envenenadas: el desdén, el olvido, el paso del tiempo, mientras se añora la lluvia que no se repetirá, o aquellas noches de verano que no han de volver. El jardín cerrado, el huerto clausurado, heredado de la mejor tradición poética, es aquí denuncia de la cosecha de la devastación.

No puede un libro de poesía cerrarse así, y son las dos últimas secciones las que van a procurar la superación de la adversidad y demostrar que la búsqueda iniciada a lo largo del libro puede llegar a tener resultados positivos. 
Para ello, Bagué procede a un exigente y severo proceso de autoanálisis, de ingreso en la introspección frente a los fragmentos de un espejo, que culmina en un espléndido «Autorretrato», poema digno de la mejor antología contemporánea. Poema que, en definitiva, nos integra plenamente en el transcurso antes señalado, en el que los objetos, los libros personales o las fotos antiguas, ajustarán cuentas a poeta y amada. Justamente, la estructura doble del poema «Álbum de fotos» nos advierte de que el autor no está solo en este sufrir las agresiones del pasado, sino que tiene quien comparte con él su mismo destino.

El libro se cierra con un grupo de poemas reunidos con el muy expresivo título de «Paraíso perdido», en el que las representaciones poéticas recuperan la indagación y la búsqueda de mundos que, aunque huidos, son revividos desde un presente distinto. Las muchas veces condenada desmemoria se supera con la deleitosa recuperación de objetos y miradas que devuelven al poeta aquel paraíso que se fue. Una vez más es la palabra poética la que se encarga de convertir en indeleble el sonido de un viejo disco, las aventuras de una novela familiar, los rostros absortos de una recordada pintura o la magia permanente de un poema inmortal, junto al mito siempre sobrecogedor de una Ofelia intensamente simbólica.

Reencontramos aquí al poeta nuevo, perteneciente a la primera promoción del siglo xxI, que sabe crear universos poéticos inteligentes, que domina las estructuras poemáticas con envidiable soltura y que prodiga un estilo limpio y natural, mantenido a lo largo de todo el libro con rigor y cohesión. Desde las propias vivencias personales, el poeta sabe además universalizar sentimientos y comprometer a su lector en esta nueva reflexión poética, a la luz de una clara modernidad y de su visión irónica de la vida contemporánea, que ha ido forjando la palabra poética del autor y afirmándose una indiscutible y original personalidad en su visión del mundo. Ya lo señaló uno de sus más fieles lectores, Joaquín Juan Penalva, quien aseguraba que, con Página en construcción, Bagué consolida una voz que había ido configurándose desde los tiempos de Telón de sombras, y advierte que su poesía ha ido construyendo un interesante sujeto poemático que, poco a poco, se fue despojando de elementos culturalistas y literarios para alcanzar una mayor independencia en la expresión de sus reflexiones, de manera que Bagué «ha pasado de una elegía no confesional a una poesía más autobiográfica, aunque sin abandonar las técnicas y fórmulas que le sirvieron para construir su voz. El título del volumen, por tanto, tiene una doble lectura: 'vida en construcción' y 'obra en marcha'» ${ }^{6}$. En la nueva poesía hallaremos entonces una convivencia de los referentes culturales con el componente confesional.

6 Joaquín Juan Penalva, «Vivencias hechas verso», Diario Información, 29 de junio de 2011. 
En efecto, en Página en construcción ${ }^{7}$ descubrimos a este poeta de la primera generación el siglo XXI con una trayectoria poética ya consolidada, que confirma al ofrecer una serie de representaciones poéticas basadas en un inteligente análisis de la realidad más próxima, vista esta última con una desenfadada distancia entre irónica y, al mismo tiempo, complaciente. Se sirve Bagué de un lenguaje poético que ha acuñado con personalidad, en el que entran en juego los manidos conceptos de nuestra existencia contemporánea reconvertidos en miradas sobre el mundo que rodea al poeta y que el propio autor pretende que, del mismo modo, circunde y convenza al lector. Palabras de nuestro tiempo, de la desgastada existencia cotidiana que, enfocadas desde un prisma distanciador, designan aspectos de la realidad que merecen ser advertidos bajo un prisma de renovación.

Nótense por ejemplo las sugerencias semánticas que suscita el título del libro, Página en construcción, tomado del lenguaje de la informática, pero asumido con todo su significado para descubrir la actividad del poeta como artífice laborioso que está construyendo su libro de igual modo que el informático construye su página. Y la propia palabra «construcción», que puede relacionarse con el moderno concepto estructuralista de la «deconstrucción», la hallaremos en el título de un poema que, al mismo tiempo, muestra una desenfada representación del mundo. Por su parte, la composición titulada «De construcción» alude justamente a la necesidad de construir un orden aceptable en un mundo trastornado en el que precisamente las palabras no significan lo que debieran.

Y podemos reparar en otros títulos de poemas de este libro y advertiremos un proceso similar, con el que el poeta pretende ante todo superar lo vulgar, lo repetido, lo que carece de interés. Así ocurre en «Estética de la decepción», que alude a la estética de la recepción como proceso establecido en los estudios filológicos, pero que, en realidad, representa una visión de ese mundo entrevisto entre pronombres que, evocando a Pedro Salinas, los considera una cárcel de amor en originalísima reconversión no exenta de cierto sarcasmo. «La duda retórica», otro de los poemas, alude sin ambages a la duda metódica y una latina cita de Descartes deja pocas posibilidades al encuentro burlesco entre ansiedad y duda, en un análisis muy riguroso de un mundo que evoca errores trascendentes de la historia, y que al poeta no hace sino producirle eso: una duda, pero nada retórica, desde luego.

Los poemas a los que nos estamos refiriendo pertenecen a la cuarta parte del volumen de las cinco en que esta ordenado, la titulada «Ensayos». Las otras cuatro son «Historias», «Metarrelatos», «Hipótesis» y «Monólogos», que es la que se encarga de cerrar el libro, compuesta por dos poemas con importantes ecos mitológicos: «El sueño de Ulises» $\mathrm{y}$ «El síndrome de Ca-

7 Luis Bagué, Página en construcción, Madrid, Visor, 2011. 
sandra». Suponen ambos una recuperación de dos historias sabidas, ahora envueltas en inquietudes ante nuestro mundo y ante el tiempo presente. Los mitos, por tanto, son los encargados de cerrar un libro inteligente, atribuyéndose a su estela mitológica la imposibilidad de comprender el mundo.

«Carta de ajuste», «Lavado rápido», «Fast food» son los títulos de poemas pertenecientes al sector de «Ensayos», en los que se sigue comprometiendo en su visión del mundo aportando, en esta ocasión, una visión más moral de la existencia y delatando limitaciones que se advierten entre las irónicas metáforas de los poemas. Una realidad que descubre un mundo cosmopolita (escenarios de La India) recientemente incorporado que manifiesta su evidente y decepcionante realidad.

Sin duda, como en los restantes apartados del libro, Bagué reivindica orden para un mundo muchas veces tan incomprensible como injusto e insolidario. Por lo menos tal impresión parece entreverse en las numerosas representaciones de una realidad reconstruida formalmente, que supera la propia y estricta realidad. Si hubo una «poesía de la experiencia» que creó discípulos inseguros, la de Luis Bagué, que conoce muy bien esa influyente tendencia poética por haberla estudiado en profundidad, es una poesía más allá de la experiencia, que pretende, junto a una imposible comprensión de un mundo incomprensible, hallar un camino para transitar por él sin sufrir mayores lesiones, como si la palabra poética de Luis Bagué se convirtiera en una cartografía para poder navegar en eso que él denomina, siempre con esa serena ironía que cohesiona este libro poético, «world in progress», no sabemos muy bien si buen o mal progreso el de este mundo controvertido. Juan Carlos Abril se refirió a este juego de palabras con «work in progress», y señaló que nos hallamos ante un contexto en movimiento: «La lógica nos explica desde el primer instante, desde el título, que el poeta está aludiendo a una forma de ver el mundo, a una filosofía moral y política, también a una ética» ${ }^{8}$. Pero advierte también del mismo modo que hay también un lenguaje tipificado, una forma de estructurar el sentido -o sinsentido-de las cosas, para que llegue cualquier proceso empírico a convertirse en poesía y poder ser compartido. También la idea mallarmeana de la página en blanco podría erigirse como símbolo de lo que se tiene que construir...

Un aspecto señalado por José Gutiérrez Román pone de relieve, como indudable signo de modernidad o de contemporaneidad, la presencia de la música, a través de las citas de canciones de Bob Dylan, Joy Division, David Bowie, La Habitación Roja y The Jam: «La música hace su aparición en la segunda parte con las citas que acompañan a cada poema, pertenecientes en su mayoría a canciones emblemáticas de la historia del pop y el rock» ${ }^{9}$.

8 Juan Carlos Abril, «A pie de andamio», Monteagudo, 17, 20I2, p. 235.

9 José Gutiérrez Román, «Página en construcción», La Tormenta en un Vaso, 2I de junio de 20II, consultable bajo el enlace http://latormentaenunvaso.blogspot.ch/20II/o6/pagina-en-cons- 
La ironía no exenta de un tono de decepción ante los reclamos del mundo contemporáneo define también el tono de estos poemas.

En Paseo de la identidad ${ }^{\mathrm{1}}$, experimenta Bagué un nuevo paso, un avance más en el mundo de su poesía que parte del concepto sugerido por un paraje visitado en Iguazú, Argentina, con el nombre de Paseo de la identidad, que figura en la imagen de la cubierta del libro. Porque, desde luego, aunque el poemario recoge paisajes y espacios diversos visitados, y podría parecer un libro de viajes y geografías alucinantes, no es sino un ejercicio de profundización en la propia «identidad», tal como sugiere el título del poemario y la fotografía que ilustra su portada.

En todo caso, la técnica empleada para ahondar en un mundo poético incisivo y penetrante, es similar a la del collage, ya que conjunta espacios remotos (USA, Argentina, Europa) para estructurar su poemario en tres partes de diferente extensión: «Mecánica terrestre», «American Landscapes» y «Escala real». Y cada una de ellas acoge poemas que son fragmentos de existencia ante una realidad insólita, a veces retenida en composiciones muy breves, de uno o dos versos nada más. Aunque en otras ocasiones se demora y extiende en escenas admirablemente conseguidas, con toda su dosis de vida cotidiana y de inevitable asombro ante el instante, como ocurre en dos poemas antológicos: «Oración en Starbucks» o «Biología marina», pertenecientes a «Mecánica terrestre». José Enrique Martínez ve en la abundancia de nombres propios y en la mezcla de lo banal con lo serio, la ironía y las alusiones a los usos modernos de la técnica (cine, informática, automóviles, etc.) «ciertas marcas vanguardistas adecentadas para el presente»"

Es muy destacable en la construcción del mundo poético de Bagué en este libro, como en otros anteriores suyos, el sentido del humor y la ironía que, a veces, se consigue con la nueva formulación de frases hechas sorprendentemente deformadas como si quisiera mostrar un mundo cotidiano en descomposición y en crisis, en el que el poeta es un ciudadano absorto y sufriente, para mostrar que tanto la identidad del poeta como la del mundo no son en realidad lo que parecen sino que están sometidas a presiones muy intensas. Así lo señaló también Juan Carlos Abril cuando afirmó que, junto a las imágenes incisivas, los homenajes y los guiños pictóricos o cinematográficos, «en este libro brillan la ironía, los juegos de palabras, las frases hechas pero deformadas, traídas por los pelos, cambiadas de sentido, transfiguradas» ${ }^{12}$.

Y, en ese sentido, el intermedio norteamericano, con sus imágenes rete-

truccion-luis-bague.html [28.2.2017].

Io Luis Bagué, Paseo de la identidad, Madrid, Visor, 2014.

II José Enrique Martínez, «Una cumbre es un valle de perfil», Diario de León, I3 de julio de 2014 .

I2 Juan Carlos Abril, «Paseo de la identidad», Lectura y Signo, 9.I, 20I4, p. I28. 
nidas, es altamente representativo de las contradicciones de este mundo, un mundo capitalista posiblemente fracasado a causa de su deshumanización y su carencia de identidad, como no sea la del consumismo desmedido. En realidad, tanto esta apertura al mundo norteamericano como al argentino en otra de las partes del libro, refleja el asombro del poeta ante la inestabilidad de un mundo abierto y global en el que las sorpresas se van alternando con los accesos a la propia intimidad. Todo ello, sin duda, como expresión de la identidad del yo lírico, que sigue siendo la de un Luis Bagué poseedor de un estilo propio y de un idioma personal, en el que no faltan las predilecciones de siempre como el cine, recuperado en un «Triptico Lumière» compuesto de tres estancias, «Salida de los obreros», «Llegada de un tren»y «El regador regado», que se cierra con estos paradójicos versos, pura esencia del cine con Louis Lumière como trasfondo: «¿Qué diferencia ves / entre la filmación y lo filmado?» ${ }^{13}$.

O reflejado también en la reverencia ante la más entrañable poesía de siempre retenida en un emotivo y sintético «Yo también estuve en Colliure», reflejo de la inevitable sensación de pesadumbre histórica que comporta el lugar y su trascendencia literaria con Antonio Machado en la memoria. Identidad que es la del ciudadano del mundo contemporáneo sobrecogido ante el «Entorno Windows» que viaja en un avión de las «Narrativas argentinas», que se cita en un Starbucks, o que visita leones y lobos marinos y sobrevive en un mundo dominado por las lenguas modernas, para exclamar en el único verso del último poema, titulado «Lost in Translation»: «No volveré a escribir sobre mojado» ${ }^{14}$. El sueño del dragón produce monstruos» ${ }^{15}$ se dice de forma muy goyesca en otro poema y, con Quevedo en el fondo en otro, se asegura: «No cambia lo que solo se transforma. / Solo lo que ha cambiado permanece» ${ }^{16}$.

Un defensivo sentido del humor es la única arma de la que dispone el poeta para enfrentarse a este mundo globalizado que está perdiendo su propia identidad y está logrando que el ser humano, sensible y consciente, también pierda la suya propia. Y casi sin identidad, ya solo la ironía es capaz de salvaguardarla de la patética tragedia de una vida sin sentido, como se dice en el penúltimo poema del libro, «Traducción simultánea», en sus dos únicos versos: «Las palabras que nos salvan la vida / son las mismas que pueden condenarnos a muerte» ${ }^{17}$. Desde la ironía, nuestro rebelde poeta nos ofrece su desenfadada concepción de la existencia que nos compromete como lectores y como habitantes y ciudadanos de un mundo convulso.

I3 Luis Bagué, Paseo de la identidad, op. cit., p. 43.

I4 Luis Bagué, Paseo de la identidad, op. cit., p. 54.

I5 Luis Bagué, Paseo de la identidad, op. cit.., p. 32.

I6 Luis Bagué, Paseo de la identidad, op. cit., p. 32.

I7 Luis Bagué, Paseo de la identidad, op. cit., p. 53. 